\title{
COMPOSIÇÃO FLORÍSTICA DAS FORMAÇÕES VEGETAIS SOBRE UMA TURFEIRA TOPOTRÓFICA DA PLANÍCIE COSTEIRA DO RIO GRANDE DO SUL, BRASIL
}

\author{
César S. B. Costa ${ }^{1}$, \\ Bruno E. Irgang ${ }^{2}$, \\ Aline R. Peixoto \\ Juliano C. Marangoni ${ }^{1}$
}

Recebido em 10/08/2001. Aceito em 04/07/2002

\begin{abstract}
RESUMO - (Composição florística das formações vegetais sobre uma turfeira topotrófica da planície costeira do Rio Grande do Sul, Brasil). Turfeiras topotróficas caracterizam-se como corpos de águas rasas, permanente ou periodicamente alagados por água do lençol freático, percolada através do solo inorgânico das terras altas adjacentes à depressão central da turfeira. Possuem solos orgânicos e a cobertura vegetal é dominanda por fanerógamas aquáticas emergentes. Este estudo visou o levantamento da diversidade específica e caracterização das principais formações vegetais ao longo de duas transecções de 200m em uma turfeira topotrófica na localidade de Domingos Petrolini (Rio Grande, RS). Em março/1998, o total de 48 espécies vegetais (30 famílias) foram encontradas nas 40 parcelas de 5m $\times 2 \mathrm{~m}$ observadas nas duas transecções efetuadas. Cerca de $56 \%$ das espécies eram plantas aquáticas herbáceas (submersas, flutuantes ou emergentes) e apenas $10 \%$ arbustos ou árvores. Sete espécies dominaram a cobertura vegetal (Eupatorium tremulum, Eryngium pandanifolium, Blechnum brasiliense, Rhynchospora sp., Xyris jupicai, Utricularia gibba e Cladium jamaicense). Quatro formações vegetais tipicamente distribuídas em relação à topografia e à distância do lençol freático foram caracterizadas: (1) banhados do capim-navalha Cladium jamaicense, drenados apenas no verão, ocupam a depressão central da turfeira (DCT); (2) planos médios de Gravatás/Caraguatás (Eryngium pandanifolium) associados a samambaia Blechnum brasiliense ( $+0,5 \mathrm{a}+1,5 \mathrm{~m}$ da DCT); (3) bosques marginais de arbustos palustres (+1 a +3m da DCT) são dominados por Eupatorium tremulum; e (4) campos de turfa recobertos por ciperáceas de pequeno porte, gramas boiadeiras e botões-de-ouro (Xyris jupicai) ocupam a borda do afloramento da turfa $(+3 \mathrm{a}+4 \mathrm{~m}$ da DCT $)$.
\end{abstract}

Palavras-chave - turfeira, Cladium, Blechnum, Eupatorium, vegetação

\begin{abstract}
Floristic composition of the vegetation types of a fen on the southern Brazil coastal plain in Rio Grande do Sul, Brazil). Fens are characterized as shallow water bodies permanently or periodically flooded by groundwater table, originating from the percolation of rain water through mineral soils of uplands adjacent to the fen central basin. Fens have organic soil and their plant cover is dominat by emergent phanerophytes. This study aims to survey the specific diversity and characterize the main vegetation types along two $200 \mathrm{~m}$ transects positioned in a fen of the southern Brazilian county of Domingos Petrolini (32 $02^{\prime}$ S ; 52 $12^{\circ}$ W; Rio Grande, RS). In March/1998, 48 plant species
\end{abstract}

1 Departamento de Oceanografia, Fundação Universidade Federal do Rio Grande (FURG), C. Postal 474, CEP 96201-900 Rio Grande, RS, Brasil (docosta@ super.furg.br)

2 Departamento de Botânica, Universidade Federal do Rio Grande do Sul, Porto Alegre, RS, Brasil

3 Pós-Graduação em Botânica, Universidade Federal do Rio Grande do Sul, Porto Alegre, RS, Brasil 
(30 families) were recorded in forty $5 \mathrm{~m} \times 2 \mathrm{~m}$ plots along the two transects. Herbaceous aquatic macrophytes (submersed, flooting or emergent) represented $56 \%$ of species, but $10 \%$ were shrubs or trees. Seven species dominate the vegetation (Eupatorium tremulum, Eryngium pandanifolium, Blechnum brasiliense, Rhynchospora sp., Xyris jupicai, Utricularia gibba, and Cladium jamaicense). The vegetation types include (1) summer exposed swamps dominated by Cladium jamaicense (placed in the fen central basin; FCB), (2) intermediate level of Gravatás/Caraguatás (Eryngium pandanifolium) associated with the fern Blechnum brasiliense $(+0.5$ to $+1.5 \mathrm{~m}$ from the FCB), (3) marginal palustrine shrubs $(+1$ to $+3 \mathrm{~m}$ from the FCB) dominated by Eupatorium tremulum and (4) turf fields covered by small sedges, soft-leaved grasses with the yellow-eyed grass (Xyris jupicai) occupying the upper border of the fen ( +3 to $+4 \mathrm{~m}$ from the FCB).

Key words - fen, Cladium, Blechnum, Eupatorium, vegetation

\section{Introdução}

As turfeiras podem ser classificadas como sistemas palustres (sensu Cowardin et al. 1979), compostos por corpos de águas rasas permanente ou periodicamente alagados por água de precipitação pluviométrica, sem margem bem definida e com fundo coberto por vegetação e lodo orgânico. $O$ acúmulo no sedimento de matéria orgânica vegetal composta por celulose, lignina e outras substâncias com estrutura química cíclica de difícil degradação, combinado com condições desfavoráveis à decomposição aeróbica, como o excesso de água, ausência de oxigênio e reação ácida, facilitam o processo de humificação (formação de ácido húmico ou colóides húmicos insaturados) (Villwock et al. 1980; Damman \& French 1987). As condições ambientais acima descritas propiciam a formação de turfeiras, cujos solos apresentam frequientemente teores de carbono iguais ou maiores do que 50\% do peso seco do solo (Mitsch \& Gosselink 1986).

A maioria das turfeiras observadas na planície costeira do Rio Grande do Sul (Villwock et al. 1980; Schafer 1985; Neves \& Lorscheitter 1996) e no litoral do nordeste brasileiro (Lenz 1984) pode ser classificada quanto à forma de captação de nutrientes e evolução, como Turfeiras Topotróficas, também denominadas Turfeiras Rasas. Ao contrário de Turfeiras Altas ou Ombrotróficas ("Bogs"), dominadas pela cobertura de briófitas prostradas de aspecto esponjoso do gênero Sphagnum, e que recebem somente água de precipitação atmosférica (chuvas e neve), as turfeiras topotróficas têm o crescimento dependente do abastecimento por água do lençol freático. Devido à percolação da água do lençol freático através do solo inorgânico das terras altas adjacentes à depressão central da turfeira, esta última possui uma quantidade de nutrientes relativamente alta e sua cobertura vegetal é dominada por fanerógamas aquáticas emergentes. As turfeiras topotróficas da planície costeira do Rio Grande do Sul, geralmente, foram originadas a partir do desenvolvimento massivo de macrófitas lignificadas na depressão de lagos rasos ou vales abandonados durante o período regressivo póstransgressão Flanderiana (Holoceno), nos últimos 5 mil anos (Schafer 1985). Entretanto, Neves \& Lorscheitter (1996) demonstraram que uma mata paludosa costeira, com componentes arbustivos e arbóreos, pode desenvolver-se durante o processo de preenchimento da cava de uma turfeira topotrófica no Rio Grande do Sul. Estes autores também sugerem, através de datação radiométrica com $\mathrm{C}^{14}$, que o início da sequiência sedimentar de uma turfeira na costa norte do Rio Grande do Sul ocorreu ainda no final do Pleistoceno, a $23.800 \pm 500$ anos.

Funcionalmente uma turfeira topotrófica é muito semelhante à zona litoral dos lagos (Esteves 1988), onde macrófitas emergentes e submersas oferecem hábitat e alimento para inúmeros organismos, inclusive micro e macroalgas que se fixam nas suas folhas e hastes (Damman \& French 1987; Rowell \& Harvey 
1988). A matéria vegetal das plantas da turfeira sustenta principalmente teias alimentares de animais detritívoros (Mitsch \& Gosselink 1986), e os ciclos biogeoquímicos locais são altamente influenciados pela produção da vegetação. As turfeiras topotróficas constituem importantes fragmentos de terras alagáveis para aves e pequenos mamíferos, e verdadeiras ilhas de diversidade natural na paisagem modificada do Rio Grande do Sul (Neves \& Lorscheitter 1996). Mesmo em áreas progressivamente alteradas por atividades agropecuárias, o piso macio e constantemente alagado, bem como a presença de uma cobertura vegetal espinhosa de gravatás (Eryngium pandanifolium) e capins-navalha (e.g., Cladium jamaicense e Rhynchospora sp.) restringe o acesso do Homem e de seus animais domésticos.

Além de tentativas de catalogação (Wildner et al. 1988), caracterizações pontuais (Villwock et al. 1980; Neves \& Lorscheitter 1996) e listas de espécies (Rambo 1942; Irgang \& Gastal 1996), pouco é conhecido das turfeiras topotróficas do Rio Grande do Sul. No entanto, antes relativamente comuns no estado, estes ambientes vêm sendo destruídos por aterros e drenagens para o desenvolvimento residencial, agrícola ou industrial, bem como para extração do seu solo orgânico (a turfa). A acumulação de sedimento orgânico na turfeira é lenta (nas mais produtivas, poucos milímetros por ano), e a mineração da turfa envolve a remoção da cobertura vegetal e alteração da drenagem, que são condições básicas para o desenvolvimento destes ambientes (Lenz 1984; Abrão \& Singer 1985; Tommasi 1994). Este estudo visou o levantamento da diversidade específica e caracterização das principais formações vegetais de uma turfeira topotrófica localizada da zona sul da Planície Costeira do Rio Grande do Sul.

\section{Material e métodos}

Local de estudo - A turfeira estudada está localizada no distrito de Domingos Petrolini pertencente ao município de Rio Grande (RS). Esta turfeira denominada na cartografia do município como Banhado 25 (B25), estende-se por cerca de $13 \mathrm{~km}$ no sentido sudeste-nordeste, e apresenta uma largura máxima de $1,5 \mathrm{~km}$. Os planos mais altos da turfeira encontram-se em sua parte sudeste (8-12m acima do nível do mar), sendo que no lado nordeste a superfície da depressão central encontra-se a $6 \mathrm{~m}$ de altitude. Sondagens demonstraram que a espessura da turfa atinge até $7 \mathrm{~m}$ de profundidade em sua depressão central. Com exceção das bordas que se assentam sobre terrenos arenosos da Barreira III, o sedimento superficial possui um teor médio de matéria orgânica de $27 \%$.

Dados obtidos entre 1957 e 1977 (IPAGRO 1979) pela Estação Meteorológica do Instituto de Pesquisas Agronômicas (IPAGRO-RS) de Domingos Petrolini demonstram uma variação da média mensal de temperatura entre $13,5^{\circ} \mathrm{C}$ (julho) e $24,4^{\circ} \mathrm{C}$ (janeiro). Os valores médios anuais de precipitação e evaporação são de, respectivamente, $1.317 \mathrm{~mm}$ e $906 \mathrm{~mm}$, sendo que as médias mensais do balanço hídrico demonstram grandes superávites (+64 a $+110 \mathrm{~mm}$ ) entre junho e setembro, além de pequenos a médios déficit hídricos entre novembro e abril (-2 a $-43 \mathrm{~mm})$.

Coleta e análise dos dados da vegetação Dois pontos, representativos da diversidade estrutural da vegetação da turfeira de Domingos Petrolini, foram escolhidos após avaliação visual da cobertura vegetal por percursos de carro e a pé, bem como através da análise de fotografias aéreas verticais (Levantamento DAER 1975 e Levantamento Exército Brasileiro 1996). Os pontos localizados na porção nordeste (cortada pela BR-392) e sudeste (região mais alta próxima a cabeceira) serão designados no decorrer do texto como, respectivamente, porção norte e porção sul. Em março/1998, em cada ponto, foi demarcada uma transecção de $200 \mathrm{~m}$ perpendicular ao eixo principal da turfeira, onde foi obtido o perfil topográfico, através de 
diferença de nível, a cada $10 \mathrm{~m}$ da transecção. Para a caracterização da composição florística foram consideradas as espécies contidas em 20 parcelas de $5 \mathrm{~m} \times 2 \mathrm{~m}$, que foram coletadas, herborizadas e identificadas (Cabrera 1953; Barros 1960; Cordazzo \& Seeliger 1988; Irgang \& Gastal 1996). O maior lado de cada parcela foi posicionado perpendicularmente à transecção e as parcelas foram dispostas de forma equidistante ao longo da transecção. $\mathrm{O}$ total de 40 parcelas foram observadas nos dois pontos estudados. Espécies que ocorreram em mais do que $50 \%$ das parcelas em pelo menos uma das duas porções da turfeira foram consideradas Dominantes ("D"), enquanto espécies com frequiência entre $20-50 \%$ e menos de $20 \%$ foram classificadas, respectivamente, em Subordinadas ("S") e Ocasionais ("O"). As espécies dominantes sempre representaram a maior parte da cobertura vegetal das parcelas observadas. As principais formações vegetais foram determinadas pela cobertura vegetal dominante, que também foi utilizada para a denominação da formação. Exceto pelas parcelas que possuiam espécies dominantes com diferentes formas de crescimento (ex: arbusto ou árvore em relação às plantas herbáceas) que foram designadas à formação da dominante de maior tamanho, parcelas com mais de uma espécie dominante foram classificadas como pertencentes à formação vegetal designada pelo nome da espécie mais freqüente no ponto observado.

\section{Resultados e discussão}

A turfeira de Domingos Petrolini apresenta grande diversidade de espécies vegetais, característica de turfeiras topotróficas que recebem aporte regular de água com nutrientes de enxurradas provenientes das terras altas (Lenz 1984). As 48 espécies vegetais, de 30 famílias de plantas, foram encontradas (Tab. 1) nos dois pontos da turfeira, durante o final do verão de 1998 . Cerca de 56\% das espécies eram plantas herbáceas aquáticas (submersas, flutuantes e emergentes, sensu Esteves 1988), sendo que a maioria (44\%) eram plantas herbáceas emergentes (com a maior parte das estruturas fotossintéticas acima no nível d'água) e aproximadamente $10 \%$ arbustos ou árvores tolerantes ao alagamento periódico de suas raízes (Fig. 1a). A porção norte da turfeira apresentou maior riqueza de espécies vegetais associada a presença de arbustos ausentes na porção sul, e cerca de $36 \%$ das espécies apresentaram ampla distribuição (Fig. 1b; Tab. 1). De forma semelhante aos banhados salinos da costa gaúcha (Costa \& Davy 1992; Costa 1997), a flora da turfeira é composta por componentes de origem tropical-subtropical (e.g., Leersia hexandra) e de origem temperada (e.g., Pavonia hastata).

Sete espécies dominavam a cobertura vegetal das margens das porções norte (Eupatorium tremulum, Eryngium pandanifolium, Blechnum brasiliense) e sul (Rhynchospora sp., Xyris jupicai, Utricularia gibba), e a depressão central ao longo de toda turfeira (Cladium jamaicense). Sistemas semelhantes de turfeiras rasas dominadas por formações arbustivas abertas e/ou plantas herbáceas de grande porte ( 1,0 a 2,0m alt.), como o gênero Cladium, são encontradas em regiões tropicais do Brasil (e.g. "comunidade herbácea brejosa" descrita por Araújo et al. 1998) e em outras regiões temperadas, na América do Norte (Damman \& French 1987) e Europa (Rodwell 1984; Rowell \& Harvey 1988), sendo estas últimas denominadas de "Fens".

As plantas encontradas compõem formações vegetais tipicamente distribuídas em relação à topografia e à distância do lençol freático. Apesar do lençol freático ficar a maior parte do ano a poucos centímetros acima da superfície do solo, a microtopografia e os, respectivos, maior e menor tempos de alagamento entre a região mais baixa e mais alta da turfeira são suficientes para induzir mudanças na composição da cobertura vegetal. Quatro 
Tabela 1. Listas de espécies vegetais encontradas na turfeira de Domingos Petrolini (Rio Grande, RS) no final do verão de 1998. As espécies foram ordenadas primariamente por sua abundância relativa ("Status": $\mathrm{D}=$ dominante; $\mathrm{S}=$ Subordinada; $\mathrm{O}=$ Ocasional); local de ocorrência ( $\mathrm{A}=$ ampla distribuição; $\mathrm{N}=$ porção norte; $\mathrm{S}=$ porção sul). As formas de crescimento das plantas são também indicadas $(1=$ herbácea emergente; $2=$ herbácea submersa; $3=$ herbácea flutuante; 4 = arbusto; 5 = epífita; $6=$ árvore; 7 = herbácea de solo drenado).

\begin{tabular}{|c|c|c|c|c|c|}
\hline Espécie & Família & Nome Vulgar & Forma & Status & Local \\
\hline Eryngium pandanifolium Cham. \& Schltr. & Apiaceae & gravatá/caraguatá & 1 & $\mathrm{D}$ & A \\
\hline Blechnum brasiliense Desv. & Blechnaceae & samambaia & 1 & $\mathrm{D}$ & A \\
\hline Cladium jamaicense Crantz & Cyperaceae & capim-navalha & 1 & $\mathrm{D}$ & A \\
\hline Utricularia gibba $\mathrm{L}$. & Lentibulariaceae & $\begin{array}{l}\text { boca-de-leão } \\
\text { do banhado amarela }\end{array}$ & 3 & $\mathrm{D}$ & $\mathrm{A}$ \\
\hline Eupatorium tremulum Hook. \& Arn. & Asteraceae & vassoura & 4 & $\mathrm{D}$ & $\mathrm{N}$ \\
\hline Rhynchospora sp. & Cyperaceae & capim-navalha & 1 & $\mathrm{D}$ & $\mathrm{S}$ \\
\hline Xyris jupicai (L.) C. Rich. & Xyridaceae & botão de ouro & 1 & $\mathrm{D}$ & $\mathrm{S}$ \\
\hline Baccharis cf. microcephala (Less.) DC. & Asteraceae & carqueija & 1 & $\mathrm{~S}$ & A \\
\hline Cyperus obtusatus (C.Presl.) Mattf \& Kuk. & Cyperaceae & tiririca & 1 & S & A \\
\hline Eleocharis sp. 1 & Cyperaceae & junquinho & 1 & $S$ & A \\
\hline Ludwigia sp. & Onagraceae & cruz-de-malta & 1 & $S$ & $\mathrm{~A}$ \\
\hline Leersia hexandra $\mathrm{Sw}$. & Poaceae & grama-boiadeira & 2 & S & A \\
\hline Paspalum sp. & Poaceae & grama-boiadeira & 1 & S & A \\
\hline Polygonum meissnerianum Cham. \& Schltr. & Polygonaceae & erva-de-bicho & 1 & $S$ & $\mathrm{~A}$ \\
\hline Castilleja sp. & Scrophulariaceae & - & 5 & $S$ & A \\
\hline Buddleja sp. & Buddlejaceae & barbasco/cezarina & 4 & $S$ & $\mathrm{~N}$ \\
\hline Tibouchina asperior (Cham.) Cogn. & Melastomataceae & douradinha & 4 & $S$ & $\mathrm{~N}$ \\
\hline Psidium cattleyanum Sabine & Myrtaceae & araçá & 6 & $\mathrm{~S}$ & $\mathrm{~N}$ \\
\hline Scleria hirtella $\mathrm{Sw}$ & Cyperaceae & navalha de mico & 1 & S & $\mathrm{S}$ \\
\hline Panicum helobium Nees ex Henrard & Poaceae & grama-boiadeira & 1 & $S$ & $\mathrm{~S}$ \\
\hline Nymphoides indica (L.) O.Kzl. & Menyanthaceae & estrela-branca & 3 & S & S \\
\hline Achyrocline satureoides (Lam.) DC & Asteraceae & marcela & 7 & $\mathrm{O}$ & A \\
\hline Cyperus polystachyos Rottb. & Cyperaceae & junquinho/tiririca & 1 & $\mathrm{O}$ & $\mathrm{A}$ \\
\hline Drosera brevifolia Pursh. & Drosearaceae & orvalhinha & 7 & $\mathrm{O}$ & A \\
\hline Juncus sp. & Juncaceae & junco & 1 & $\mathrm{O}$ & $\mathrm{A}$ \\
\hline Sphagnum sp. & Sphagnaceae & musgo d'água & 1 & $\mathrm{O}$ & A \\
\hline Typha domingensis Pers. & Typhaceae & taboa & 1 & $\mathrm{O}$ & A \\
\hline Cuphea sp. & Lythraceae & sete sangrias & 7 & $\mathrm{O}$ & $\mathrm{A}$ \\
\hline Hygrophila guianensis Nees. & Acanthaceae & - & 1 & $\mathrm{O}$ & $\mathrm{N}$ \\
\hline Eupatorium sp. & Asteraceae & - & 7 & $\mathrm{O}$ & $\mathrm{N}$ \\
\hline Bromelia antiacantha Bert. & Bromeliaceae & gravatá/banana do mato & 7 & $\mathrm{O}$ & $\mathrm{N}$ \\
\hline Gaylussacia sp. & Ericaceae & camarinha & 7 & $\mathrm{O}$ & $\mathrm{N}$ \\
\hline Sapium glandulatum (Vell.) Pax & Euphorbiaceae & pau-leiteiro & 4 & $\mathrm{O}$ & $\mathrm{N}$ \\
\hline Juncus scirpoides Lam. & Juncaceae & junco & 1 & $\mathrm{O}$ & $\mathrm{N}$ \\
\hline Vigna sp. & Fabaceae & caupi & 1 & $\mathrm{O}$ & $\mathrm{N}$ \\
\hline Pavonia hastata Cavanilles & Malvaceae & - & 7 & $\mathrm{O}$ & $\mathrm{N}$ \\
\hline Andropogon sp. & Poaceae & rabo de burro & 7 & $\mathrm{O}$ & $\mathrm{N}$ \\
\hline Monnina sp. & Polygalaceae & - & 7 & $\mathrm{O}$ & $\mathrm{N}$ \\
\hline Thelypteris interrupta (Willd.) K. Iwats. & Thelypteridaceae & samambaia & 1 & $\mathrm{O}$ & $\mathrm{N}$ \\
\hline Galium latoramosum (Hook \& Arn.) Clos & Verbenaceae & - & 7 & $\mathrm{O}$ & $\mathrm{N}$ \\
\hline $\begin{array}{l}\text { Limnobium laevigatum } \\
\text { (H.B. ex Willd.) Heine }\end{array}$ & Hydrocharitaceae & - & 3 & $\mathrm{O}$ & $\mathrm{N}$ \\
\hline Centella asiatica $(\mathrm{L}$.$) Urb.$ & Apiaceae & pé de cavalo & 3 & $\mathrm{O}$ & $\mathrm{S}$ \\
\hline Baccharis trimera DC. & Asteraceae & carqueja & 7 & $\mathrm{O}$ & $\mathrm{S}$ \\
\hline
\end{tabular}


Tabela 1 (continuação)

\begin{tabular}{|c|c|c|c|c|c|}
\hline Espécie & Família & Nome Vulgar & Forma & Status & Local \\
\hline Eleocharis sp. 2 & Cyperaceae & junquinho & 7 & $\mathrm{O}$ & $\mathrm{S}$ \\
\hline Utricularia tricolor St. Hill. & Lentibulariaceae & $\begin{array}{l}\text { boca-de-leão do banhado } \\
\text { rosa }\end{array}$ & 2 & $\mathrm{O}$ & $\mathrm{S}$ \\
\hline Mayaca cf. sellowiana Kunth. & Mayacaceae & musgo d'água & 3 & $\mathrm{O}$ & S \\
\hline Erianthus treinii (Hack.) Hack. & Poaceae & espanador & 7 & $\mathrm{O}$ & $S$ \\
\hline Ischaemum sp. & Poaceae & grama-boiadeira & 7 & $\mathrm{O}$ & $\mathrm{S}$ \\
\hline
\end{tabular}

formações vegetais foram caracterizadas pelas espécies dominantes dentro da turfeira: (1) depressão central ou banhados, dominados pelo capim-navalha; (2) planos médios, dominados por gravatás; (3) bosques marginais de arbustos palustres e (4) campos de turfa (Fig. 2a, b).

Maior desenvolvimento dos banhados dominados por Cladium jamaicense na turfeira de Domingos Petrolini é observado em áreas 2 a $4 \mathrm{~m}$ abaixo do nível das bordas da turfeira (onde inicialmente aflora em superfície a turfa) (Fig. 2a, b). Como em várzeas de lagoas costeiras no litoral do Estado do Rio de Janeiro (Araújo et al. 1998) e em outras localidades do hemisfério norte (Rowell \& Harvey 1988; Rodwell 1984; 1991), nestas áreas baixas o sistema de rizomas e raízes do Cladium jamaicense permanece submerso a maior parte do ano, mas geralmente não é alagado durante o verão. No caso de latitudes temperadas, o alagamento no inverno ajuda a proteger os brotos de novas hastes contra a ação das geadas (Rodwell 1984). Extenso sistema de aerênquima estende-se através das raízes, rizomas, hastes e folhas auxiliando a planta sobreviver em solo alagado anaeróbico (Crawford 1989). Segundo Rodwell (1984), Cladium tende a dominar áreas ricas em cálcio, mas pobres em nitrato e fósforo. Na planície costeira do Rio Grande do Sul, além de dominar banhados de águas doces e ácidas (Irgang \& Gastal 1996), Cladium jamaicense ocorre em pisos superiores de banhados salgados, às margens do estuário da Lagoa dos Patos (Costa et al. 1997), e pode invadir e dominar a cobertura de áreas desalinizadas devido as alterações da hidrodinâmica por aterros ou drenagens.
A

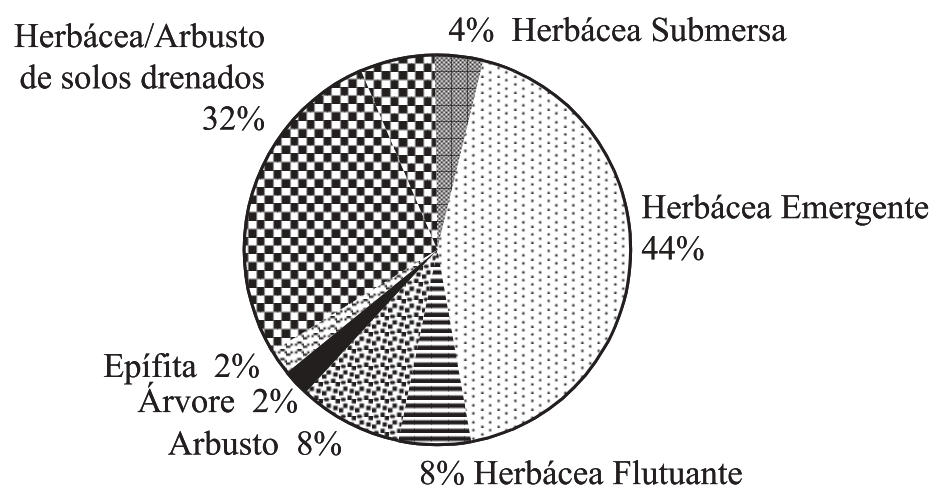

B

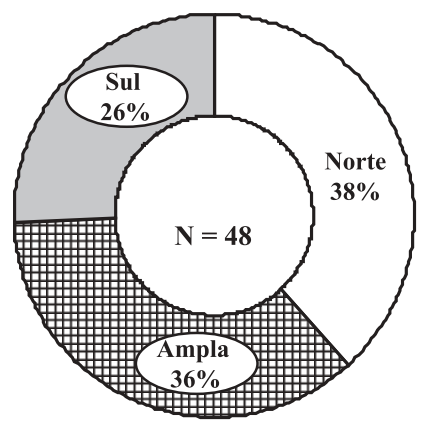

Figura 1. Caracterização da flora da turfeira de Domingos Petrolini (Rio Grande, RS) quanto às formas de crescimento (A) e a distribuição espacial (B) das espécies encontradas. 


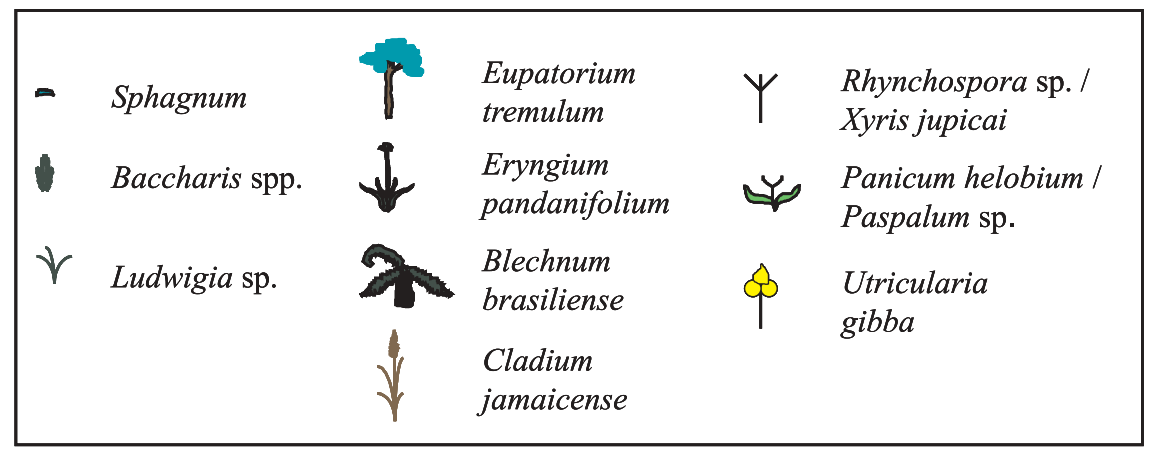

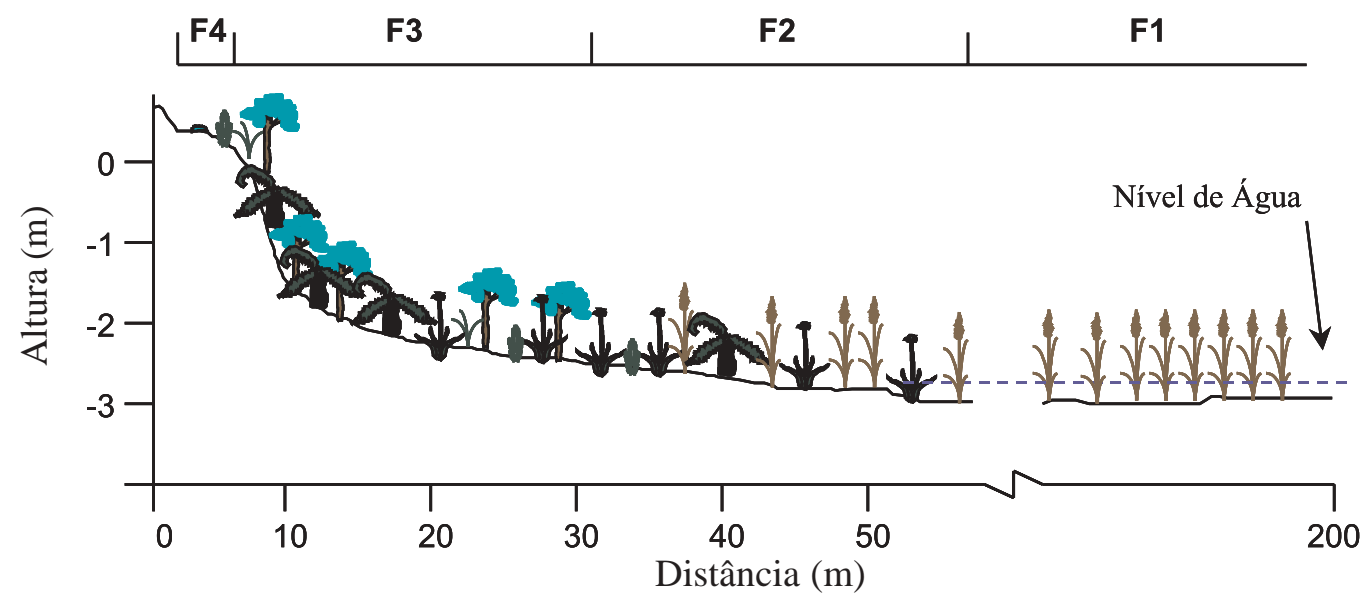

F4
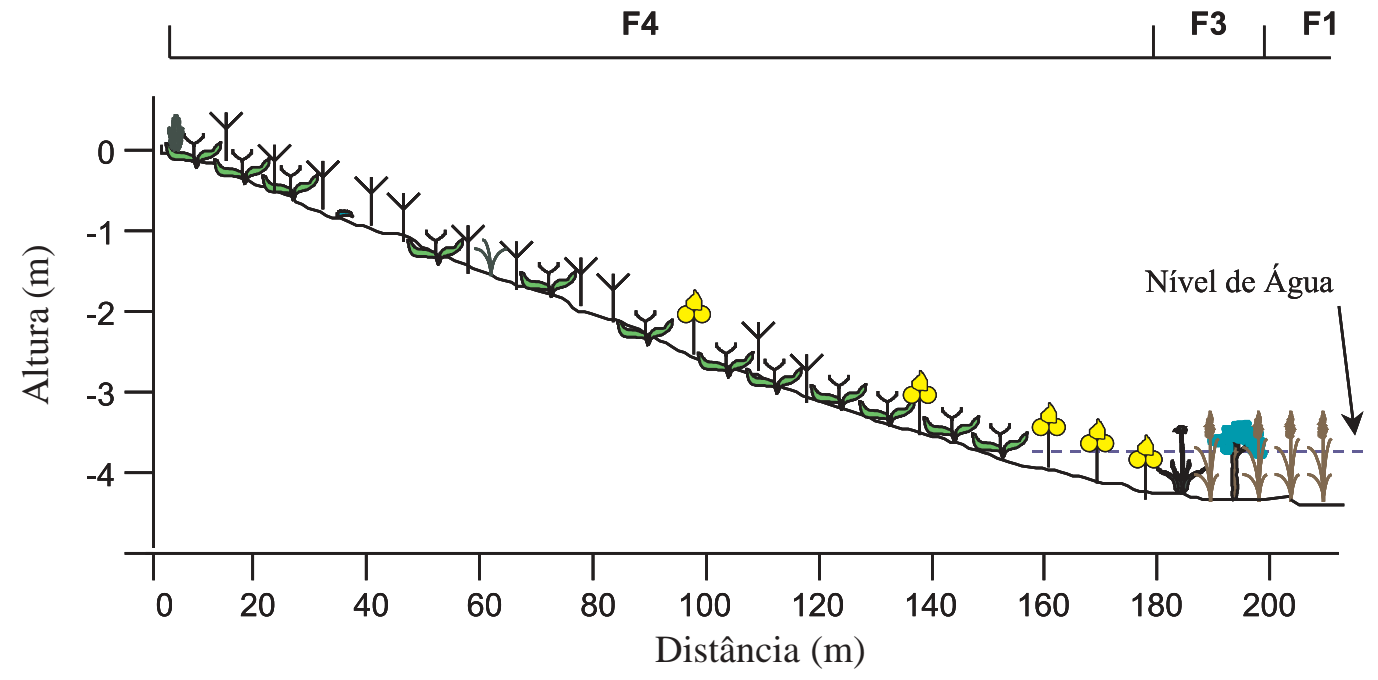

Figura 2. Diagramas da cobertura vegetal nas porções norte (a) e sul (b) da turfeira de Domingos Petrolini (Rio Grande, RS). A distribuição espacial das formações vegetais é também apresentada: (F1) Banhados de Capim-navalha; (F2) Planos Médios de Gravatás; (F3) Bosques Marginais de Arbustos Palustres; e (F4) Campos de Turfa. Diferentes escalas horizontais foram utilizadas nos perfis para facilitar a visualização das trocas topográficas e vegetacionais. 
A turfeira de Domingos Petrolini apresenta declive mais acentuado de suas margens na sua porção norte (proximidades da BR-392) (Fig. 2a). Nesta região, extensas áreas localizadas de 0,5 a $1,5 \mathrm{~m}$ acima da depressão central, constituem Planos Médios de Gravatás. Estes planos são alagados menos freqüentemente do que os Banhados de Cladium, e dominados por cobertura de gravatás/caraguatá (Eryngium pandanifolium) associada a samambaia de grande porte Blechnum brasiliense e a grande variedade de plantas higrófilas de menor porte. E. pandanifolium e B. brasiliense são consideradas plantas aquáticas emergentes (Irgang \& Gastal 1996), de ampla distribuição no Rio Grande do Sul, onde crescem em solos alagados a maior parte do ano, em várzeas de rios e lagoas, em banhados e turfeiras (Neves \& Lorscheitter 1996). E. pandanifolium e Blechnum spp. foram caracterizados como espécies indicadoras de turfeiras rasas por Rambo (1942), Villwock et al. (1980) e Araújo et al. (1998). A cobertura das dominantes possui 1,2 a 1,8m de altura e é muito compacta. Subordinados, pequenos arbustos de carqueja (Baccharis c.f. microcephala) e cruzde-malta (Ludwigia sp.) dividem o espaço na superfície do sedimento com o capim-navalha, outras macrófitas herbáceas emergentes, tais como, Hygrophila guianensis e Juncus scirpoides (Irgang \& Gastal 1996), com monocotiledôneas (Bromelia antiacantha, Andropogon sp. e Paspalum sp.) e dicotiledôneas (Monnina sp. e Eupatorium sp.) características de campos úmidos (Cabrera 1953; Cordazzo \& Seeliger 1988; Irgang \& Gastal 1996). Adicionalmente, escapando da competição por luz, também foram muito freqüentes nesta formação, plantas anuais epífitas (Castilleja sp., às vezes parasita de Eryngium segundo Cabrera 1953) e trepadeiras (e.g. Vigna sp.).

Os planos mais altos da turfeira, principalmente na porção norte ( 1 a $3 \mathrm{~m}$ acima da depressão central), são dominados por forma- ções arbustivas mistas (isto é, com plantas herbáceas, arbustos e árvores), com grande diversidade de espécies vegetais, e aqui denominadas de Bosques Marginais de Arbustos Palustres (Fig. 2a). Esta formação vegetal foi dominada pela Asteraceae Eupatorium tremulum associada a Buddleja sp., Tibouchina asperior, Psidium cattleyanum, Pavonia hastata e Sapium glandulatum. Alguns destes arbustos que crescem em solos encharcados (Irgang \& Gastal 1996) podem atingir entre 2-3m alt., no entanto não possuem copa densa, o que possibilita a formação de expressivo estrato herbáceo cuja, composição é muito semelhante a dos Planos Médios de Gravatás. A formação dominada por Eupatorium tremulum demarca uma franja superior na porção norte da turfeira, sendo análoga à formação arbustiva com presença de Tibouchina urceolaris descrita para as lagoas fluminenses (Araújo et al. 1998). A única semelhança florística entre esta formação e as áreas dominadas por arbustos de ericáceas em turfeiras do nordeste dos Estados Unidos (Damman \& French 1987) é a presença de camarinhas (Gaylussacia sp.). Comunidades arbustivas com rico estrato herbáceo também são descritas para os "fens" ingleses, sendo a abundância de plantas herbáceas relacionada com o não alagamento durante parte do ano, e conseqüente exposição das camadas superficiais da turfa à atmosfera, mais rápida mineralização em ambiente aeróbico e enriquecimento de nutrientes (Rodwell 1991). No limite superior da franja de arbustos, encontrou-se estreita faixa de transição para os campos adjacentes, recobertas por musgos d'água (Sphagnum sp. e Mayaca c.f. sellowiana), grama-boiadeira Leersia hexandra e outras espécies também associadas a solos úmidos arenosos (Galium latoramosum, Polygonum meissnerianum e Xyris jupicai). Esta última faixa apresentou maior afinidade, em termos de composição florística, com os Campos de Turfa encontrados na porção sul da turfeira de Domingos Petrolini. 
$\mathrm{Na}$ porção sul da turfeira, que apresenta maior altitude (8-12m acima do nível do mar), predominam planos médios e altos dominados por Campos de Turfa (campos úmidos com solo orgânico e com cobertura vegetal de pequeno porte) (Fig. 2b). Em muitos locais ao longo da porção sul da turfeira, a borda do afloramento da turfa, e conseqüentemente o limite superior dos Campos de Turfa, foram claramente demarcados por uma faixa dominada por Baccharis trimera. Os Campos de Turfa eram dominados por ciperáceas de pequeno porte (Rhynchospora sp., Scleria hirtella, Cyperus obtusatus, Eleocharis sp.), gramas boiadeiras (Leersia hexandra, Panicum helobium, Paspalum sp., Ischaemum sp.) e Xyris jupicai. Várias plantas encontradas no Campo de Turfa são espécies indicadoras de solos ácidos pobre em nutrientes. Sphagnum sp., Mayaca sellowiana, Utricularia gibba, Utricularia tricolor e Drosera brevifolia são todas plantas heliófitas e seletivamente higrófitas (Santos 1980; Schafer 1985), características de várzeas marginais com solos ácidos e pobres em nitrogênio (Rocha \& Costa 1988). Na região inferior dos Campos de Turfa (Fig. 2b), próximo da depressão central da turfeira, foi comum a presença de plantas aquáticas emergentes e flutuantes enraizadas no fundo, tais como Utricularia gibba, Centella asiatica e a Nymphoides indica. Nestas áreas, freqüentemente alagadas, Leersia hexandra constitui importante macrófita submersa. A característica herbácea destes campos de turfa é mantida, em parte, pelo seu uso tradicional como áreas de pastagem extensiva, fornecendo suplemento alimentar importante para o gado, principalmente durante períodos de seca ou durante invernos rigorosos.

A comunidade vegetal da turfeira topotrófica de Domingos Petrolini apresenta uma estrutura espacial zonada, com distintas formações vegetais herbáceas e arbustivas, caracterizáveis por suas espécies dominantes, distribuindo-se a diferentes alturas da depressão central da turfeira. O pequeno desenvolvimento do Bosque Marginal de Arbustos Palustres na cabeceira da turfeira (parte sul) levanta questões sobre uma possível limitação de enraizamento relacionada a um solo menos compacto ou à persistência de condições anóxicas, devido à capacidade de retenção de água do solo orgânico, mais espesso na parte sul. Resultados de Neves \& Lorscheitter (1996) demonstram que o prenchimento da cava de turfeiras topotrófica no sul do Brasil pode ser o resultado de alternância sucessiva de componentes arbustivos-arbóreos e herbáceos, em uma mesma localidade, ao longo de centenas de anos. Aparentemente, processos mais complexos do que a simples substituição serial de herbáceas por arbustivas podem ocorrer em turfeiras. Melhor caracterização abiótica e estudos dos ciclos de vida das espécies dominantes deste ecossistema são necessários para melhor compreensão de suas estruturas espaciais.

\section{Agradecimentos}

Os autores agradecem aos dois revisores anônimos pelas críticas e sugestões. C.S.B. Costa foi apoiado pelo CNPq (Proc.n. 200470/88-4) e pelo Department of Ecology and Evolutionary Biology, Brown University (EUA), na fase final de redação deste trabalho e durante o desenvolvimento de pós-doutorado.

\section{Referências}

Abrão, P. C. \& Singer, E. M. 1985. Impactos ambientais na mineração: um enfoque metodológico. Pp. 329-342. In: B. H. L. Batalha \& A. S. Silvio (Eds.). Coletânea de trabalhos técnicos sobre controle ambiental na mineração. Ministério das Minas e Energia - DNPN, Brasília. Araújo, D. S. D.; Scarano, F. R.; Sá, C. F. C., Kurtz, B. C.; Zaluar, H. L. T.; Montezuma, R. C. M. \& Oliveira, R. C. 1998. Comunidades vegetais do Parque Nacional da Restinga de Jurubatiba. Pp. 39-62. In: F.A. Esteves (Ed.). Ecologia das lagoas costeiras do parque Nacional da restinga de Jurubatiba e do município de Macaé (RJ). NUPEM/UFRJ, Rio de Janeiro. 
Barros, M. 1960. Las ciperaceas del estado de Santa Catarina. Sellowia (Herbário Barbosa Rodrigues) 12: $181-450$.

Cabrera, A. L. 1953. Manual de la flora de los arredores de Buenos Aires. Editorial Acme S.A., Buenos Aires.

Cordazzo, C. V. \& Seeliger, U. 1988. Guia ilustrado da vegetação costeira. Editora da FURG, Rio Grande.

Costa, C. S. B. 1997. Tidal marsh and wetland plants. Pp. 24-26. In: U. Seeliger, C. Odebrecht \& J.P. Castello (Eds.). Subtropical convergence environments: the coast and sea in the Southwestern Atlantic. Springer-Verlag, Berlin.

Costa, C. S. B. \& Davy, A. J. 1992. Coastal plant communities of Latin America. Pp. 179-199. In: U. Seeliger (ed.). Coastal saltmarsh communities of Latin America. Academic Press, New York.

Costa, C. S. B.; Seeliger, U.; Oliveira, C. P. L. \& Mazo, A. M. M. 1997. Distribuição, funções e valores das marismas e pradarias submersas no estuário da Lagoa dos Patos (RS, Brasil). Atlântica, Rio Grande 19: 65-83.

Cowardin, L. M.; Carter, V.; Golet, F. C. \& LaRoe, E. T. 1979. Classification of wetlands and deepwater habitats of the United States. FWS/OBS-79/31. US. Fish and Wildlive Service, Washington.

Crawford, R. M. M. 1989. Studies in plant survival. Blackwell Scientific Publications, Oxford.

Damman, A. W. H. \& French, T. W. 1987. The ecology of peat bogs of the glaciated northeastern United States: a community profile. Biological Report, 85: (7.16). US. Fish Wildlife Service, Washington.

Esteves, F. A. 1988. Fundamentos de Limnologia. Editora Interciência/FINEP, Rio de Janeiro.

IPAGRO - Instituto de Pesquisas Agronômicas. 1979. Observações meteorológicas no estado do Rio Grande do Sul. Boletim Técnico do IPAGRO. Volume 3. Secretaria de Agricultura/RS, Porto Alegre.

Irgang, B. E. \& Gastal, C. V. S., Jr. 1996. Macrófitas aquáticas da planície costeira do RS. Irgang \& Gastal, Porto Alegre.

Lenz, G. R. 1984. Turfa - métodos de lavra e opções para o uso no nordeste brasileiro. Revista Brasileira de Geociências 14(2): 111-119.
Mitsch, W. J. \& J. G. Gosselink. 1986. Wetlands. Van Nostrand Reinhold, New York.

Neves, P. C. P. \& Lorscheitter, M. L. 1996. Feições de uma mata tropical paludosa em Terra de Areia, planície costeira norte, Rio Grande do Sul, Brasil. Notas Técnica (CECO/UFRGS) 9: 28-38.

Rambo, B. 1942. A Fisionomia do Rio Grande do Sul. Jesuítas no Brasil. Livraria Selbach, Porto Alegre.

Rocha, C.T. \& Costa, C.S.B. 1988. Ordenação e distribuição das macrófitas vasculares de um pequeno lago de águas doces e rasas em Rio Grande (RS). Ciência e Cultura 40(2): 164-172.

Rodwell, J. 1984. Swamps and tall-herb fens: draft account for national vegetation classification scheme. Nature Conservancy Commission, London.

Rodwell, J. 1991. British plant communities: woodlands and scrub. Vol 1. Cambridge University Press, C.U.P., Cambridge.

Rowell, T. A. \& Harvey, H. J. 1988. The recent history of Wicken Fen, Cambridgeshire, England: a guide to ecological development. Journal of Ecology 76: 73-90.

Santos, E. 1980. Droseraceae. In: P.R. Reitz (Ed.). Flora Ilustrada Catarinense. Herbário Barbosa Rodrigues, Itajaí.

Schafer, A. 1985. Fundamentos de ecologia e biogeografia das águas continentais. EDUNISUL/GTZ, Porto Alegre.

Tommasi, L. R. 1994. Estudo de impacto ambiental. CETESB/Terragraph Artes e Informática S/C Ltda., São Paulo.

Villwock, J. A.; Dehnhardt, E. A.; Loss, E. L. \& Hofmister, T. 1980. Turfas da província costeira do Rio Grande do Sul - Geologia do depósito Águas Claras. Pp. 500-512. In: Anais do XXXI Congresso Brasileiro de Geologia. Volume 1. Sociedade Brasileira de Geologia, Balneário Camboriú.

Wildner, W.; Lopes, J. \& Camozzato, E. 1988. Turfa na província costeira do Brasil meridional, do Chuí à Laguna. Pp. 2514-2527. In: Anais do XXXV Congresso Brasileiro de Geologia. Volume 5. Sociedade Brasileira de Geologia, Salvador. 